\title{
The Role of Artificial Intelligence and Smart Classrooms during COVID-19 Pandemic and its impact on Education
}

\author{
Fatima Maqbool \\ Electrical Engineering and Engineering \\ Management Department \\ Institute of Business Management, \\ Karachi, Pakistan \\ fatima.maqbool@iobm.edu.pk
}

\author{
Seema Ansari \\ Electrical Engineering and Engineering \\ Management Department \\ Institute of Business Management, \\ Karachi, Pakistan \\ seema.ansari@iobm.edu.pk
}

\author{
Pablo Otero \\ Telecommunication Engineering \\ Department, \\ University of Malaga, \\ Malaga, Spain \\ por@uma.es
}

\begin{abstract}
Artificial Intelligence (AI) technology has revolutionized the education sector in terms of conducting classes. Especially during Covid-19 which affected significantly the education community resulting in the shift towards online learning rather than conventional classroom teaching. This study involves experiential learning during the Covid-19 lockdown situation in the field of education, learning, and teaching. It discusses how education practitioners can deal with the Covid-19 pandemic using the benefits of AI. AI innovation in the education sector has contributed not only to education but also to human development. This research aims to identify the current situation of online classes and to propose a hybrid model of Education Management Systems (EMS) and Machine Learning (ML).
\end{abstract}

Keywords---Artificial Intelligence, Education Management System, Machine Learning

\section{INTRODUCTION}

Today's world has witnessed tremendous innovation in the field of Information and Technology, especially in education sector [1]. Recent studies in the field of AI have revealed that computers have gained certain degrees of consciousness, a feature that gives machines the ability to merge modern algorithms with deep machines learning experiences for the purpose of solving complex issues related to human [2]. The role of AI in education is to facilitate teaching by eliminating time consuming tasks, such as assessment, grading and record keeping [3]. In the recent year 2020, due to the Covid-19 lockdown many institutions shifted towards online education [4]. The novel corona virus (Covid-19) has wreaked havoc across the globe. It has affected almost all the sectors of the states. Educational sector has been significantly affected due to the lockdown amid the Covid-19. Institutions shifted towards online teaching from physical classrooms. This has halted the educational processes.

In order to facilitate education, AI technology and Smart Classrooms can be used. For this purpose, AI technology, Artificial Teaching Assistant (ATA) can be placed into classrooms to facilitate learning in smart Classrooms [5]. Smart Classrooms refers to technologically enhanced setting which has capacity to increase opportunities for learners to get themselves engaged actively in learning and teaching exercise with the help of technological toots and devices [6]. This research aims to obtain satisfaction of faculty and students through online education, to identify the current tools available for conducting classes online, to identify the learning Management systems that facilitate facultystudent's communication and to identify the disaster management mechanisms available/applied that would support the online education. This paper seeks to investigate the role AI and Smart Classrooms during Covid-19 pandemic and its impact on education. This paper proposes a hybrid model of Learning Management System (LMS) and Machine Learning (ML). The rest of the paper presents State of the Art in Section-2, with comparative analysis of the Traditional Classroom and Smart Classroom. While Section-3 explains the research methodology followed by results and discussions in Section- 4 and Conclusion in Section-5.

\section{LITERATURE REVIEW}

AI holds wide range of applications in almost every field and aspect of life. It has become an essential component in the present era to solve complex problems using AI technology. In [7] authors have discussed the impact of pandemic on education and provided the suggestions to incorporate online learning in entrepreneurship. In [8] authors have highlighted the role of Artificial Intelligence in teaching by eliminating time consuming tasks, such as assessment, grading and record keeping. In [9] authors have addressed the gaps in the current educational system and provided a review on the roles of digital technologies in enhancing learning in educational institutions. In [10] authors have discussed the roles of smart classroom for conducting online classes. Smart classrooms can be used to increase opportunities for learners to get themselves engaged actively in learning and teaching exercise with the help of technological toots and devices. In [11] role of Artificial 
Teaching Assistant in helping teacher to conduct classes has been discussed. Artificial Teaching Assistant (ATA) can be placed into classrooms to facilitate learning in smart Classrooms. In [12], authors have explored the varying roles of teachers with Artificial Intelligence technologies. Challenges faced by teachers in adopting AI technologies are discussed and recommendation to adopt AI technologies has been provided. In today's world, education sector faces two challenges with the rising AI technology which are properly reaping the benefits of AI technology and training students and teachers to use modern AI tools [13]. In [14] authors have provided detailed analysis on AI technologies for education, learning paradigms and education data mining. In [15] a methodology has been proposed for implementing $\mathrm{AI}$ in education. AI has gained attention of many researchers in the educational domain. It has facilitated learners and teacher by enhancing opportunities for learners and also assists teachers in doing complex tasks like record keeping and assessment of the students AI has automated multiple teaching and learning activities. [16], [17], [18], [19]. Machine Learning Classification algorithms like Artificial Neural networks and KNN can be integrated with learning management system (LMS) to promote online education [20]. Machine Learning algorithms can be used to predict student's grades and performance [21]. Following are the state of the art applications of Artificial Intelligence as shown in figure 1 [22]

\section{A. Role of AI in Education}

AI has revolutionized the educational institutions. AI has gained attention of many researchers in the educational domain. It has facilitated learners and teacher by introducing tools like Artificial Teacher Assistant (ATA). ATA helps in enhancing opportunities for learners and also assists teachers in doing complex tasks like record keeping and assessment of the students [22].

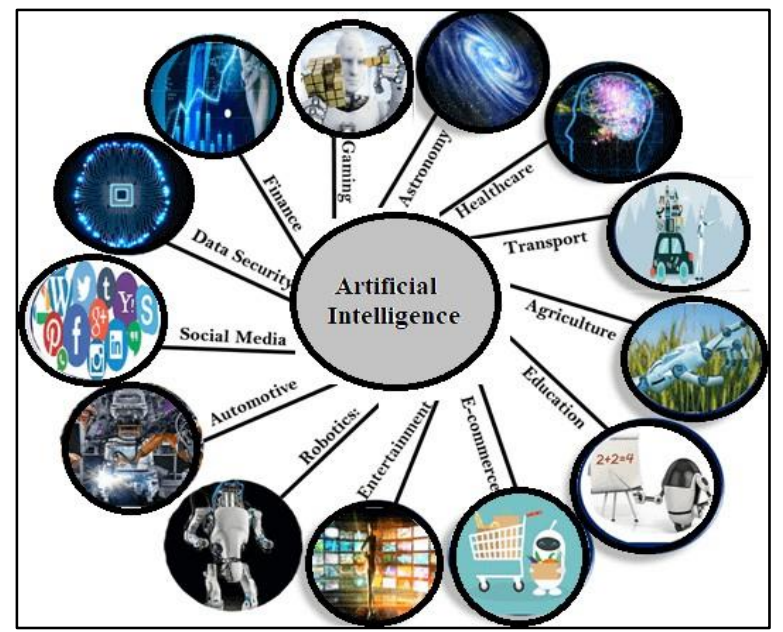

Artificial Intelligence is playing vital role in astronomy, gaming, healthcare, finance, social media, data security, travel and transport, automotive industry, robotics, entertainment and e-commerce. Many researchers are using AI based smart telescope to solve complex problem related to the space. Many astronomers are using modern AI based tools such as Machine Learning and Deep Learning Algorithms to predict the state of the Universe. Many healthcare industries have adopted AI technologies for better diagnosis.

AI technology assists doctors with diagnoses. It helps in remote monitoring of the patients. Doctors can easily keep the data of patient for the future use with the help of AI technology. Many Automotive industries are using AI technology to provide better performance and virtual assistance to their customers. Tesla has introduced an intelligent virtual assistant named TeslaBot. TeslaBot is used to find the magnitude of electric it and it is also known as Gieger Counter. Multiple Industries are using AI algorithms for creating driver free or self-driven vehicles. Agriculture is one of the most important sector for every country because it impacts directly on the economy.

This sector needs multiple resources such as labor, money, and time for accurate results. In today's world this sector is becoming digitalized for the efficient farming. Many developed countries have implemented AI algorithms such as agriculture robotics, solid and crop monitoring and predictive analysis to make agriculture sector more precise and efficient. AI technology is giving competitive edge to the e-commerce industries. It has become highly demanded technology for e-commerce business. AI assists shoppers to discover related products with suggested brand, size and color. Social Media sites like TikTok, Twitter, Facebook and Snapchat have billions of registered users' profile, which need to be managed efficiently. AI technology is expert in storing and managing data. AI helps in analyzing data to identify the latest trends, hashtag, and requirement of different users [22].

\section{B. Smart Classroom and its Impact on Education During COVID-19}

Smart classrooms refer to the classrooms where technology is efficiently used for teaching and learning. Smart classrooms refer to high power computer, proper internet connection and virtual assistant to assist teacher and students.

With the help of smart classrooms, one can easily save time and enhance productivity. It helps in making session more interactive and productive. Table 1 is showing the comparison between smart classrooms versus traditional classrooms [24].

Fig. 1 Application of Artificial Intelligence 
Table 1 Traditional Classrooms vs Smart Classrooms [24]

\begin{tabular}{|c|c|}
\hline Traditional Classrooms & $\begin{array}{c}\text { Smart } \\
\text { Classrooms }\end{array}$ \\
\hline $\begin{array}{l}\text { Traditional Classrooms } \\
\text { have fixed time. }\end{array}$ & $\begin{array}{l}\text { Smart Classrooms have } \\
\text { flexible timing. Student } \\
\text { can take help anytime, } \\
\text { anywhere. }\end{array}$ \\
\hline $\begin{array}{l}\text { In Traditional } \\
\text { Classrooms, there is a } \\
\text { homogenous group, } \\
\text { students belong to same } \\
\text { class. }\end{array}$ & $\begin{array}{l}\text { In Smart Classrooms, } \\
\text { there is a heterogeneous } \\
\text { group, people across the } \\
\text { globe are connected with } \\
\text { each other. }\end{array}$ \\
\hline $\begin{array}{l}\text { Traditional Classrooms } \\
\text { are insturctor centric. }\end{array}$ & $\begin{array}{l}\text { Smart Classrooms are } \\
\text { technology centric. }\end{array}$ \\
\hline $\begin{array}{l}\text { In Tradition Classrooms } \\
\text { teacher is responsible for } \\
\text { assessment and record } \\
\text { keeping. }\end{array}$ & $\begin{array}{l}\text { In Smart Classrooms } \\
\text { virtual assistant perform } \\
\text { assessment of students } \\
\text { and do record keeping. }\end{array}$ \\
\hline $\begin{array}{l}\text { In } \\
\text { Classrooms students are } \\
\text { graded on the basis of } \\
\text { assignments, quizzes and } \\
\text { exams. }\end{array}$ & $\begin{array}{l}\text { In Smart Classrooms } \\
\text { students are graded } \\
\text { automatically on the } \\
\text { basis of performance and } \\
\text { learning. }\end{array}$ \\
\hline
\end{tabular}

\section{RESEARCH METHODOLOGY}

This section presents four phased research methodology, AI based tools for facilitating education and a hybrid model to ensure quality education.

\section{A. Four Phased Methodology}

Methodology of this research comprises of four phases. Figure 2 is showing the pictorial representation of Research Methodology. Detail of each phase is discussed below:

1) Phase 1 - Literature Review:In Phase-1 of the research, a detailed literature review has been performed regarding Covid-19 impact of education sector. This research involves comprehensive study on the Artificial Intelligence and smart classrooms in facilitating online education. Literature review has showed the enormous role of Artificial Intelligence in the field of education.

2) Phase-2 Data Collection:In Phase 2, online questionnaire was given to faculty and students to take their input on online education. Ten faculty members and forty-seven students have responded to the survey. In the survey multiple close ended and open ended questions were asked related to online education. Students and faculty input on the tools for conducting online classes, doing communication, sharing material/content and existence of Failure Management Systems has been taken.

3) Phase-3 Data Analysis: This phase involves the evaluation of survey on the basis of input received from faculty and students. This phase involves the identification of online education prospects and the challenges faced by faculty and students in conducting online classes. Graphs have been plotted on the basis of input obtained from faculty and students.

4) Phase 4 - Proposed Model: In this phase, we proposed a model to facilitate online education. The proposed model is based on implementation of Artificial Intelligence technology to support online education. The proposed methodology involves Artificial Intelligence tools for education and pathway to implement Machine Learning integrated with Learning Management System.

\section{B. Artificial Intelligence Based Tools for Education}

Artificial Intelligence possesses many tools which can be adopted by educational institutions to facilitate learning. Artificial Intelligence can help instructor and learners by providing virtual assistance. Virtual assistant is capable to communicate with the students directly.

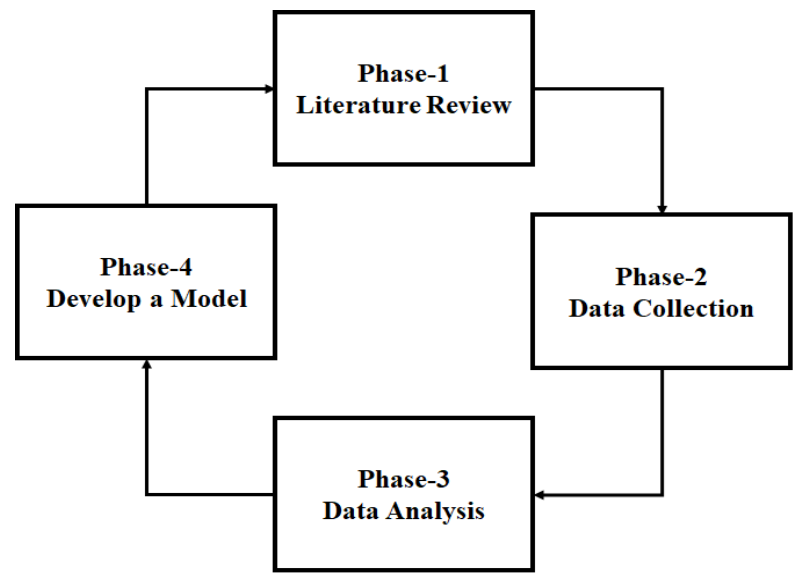

Fig. 2 Research Methodology

AI tools are also capable of predicting students' performance and grades [25]. These tools have made academic tasks simpler by eliminating time consuming 
tasks like recording keep and assessing students. Details of the tools are given below:

1) Expert System: Expert system contains expert knowledge. This system highly trained for the specific task according to the expert knowledge of the field. With the help of Artificial Intelligence, expert system can analyze data and solve complex problems. Many developed countries of the word have adopted expert system to facilitate learning in the classrooms [26].

2) Virtual Assistants: Virtual Assistants are also known as digital assistants. Virtual assistants act as teacher. Virtual assistant can listen to the voice and can respond accordingly. They are based on reinforcement learnings. They can understand the tasks in natural language and can respond in the same language too [27].

3) Chatbots: Chatbots are used for communication between multiple people. This system is capable for both oral and written communication. Instructors can use chatbots to deliver lectures to the students. Chatbots act as a virtual assistance to answer student's queries and to assist students [28].

4) Machine Learning: Machine Learning is the advanced form of Artificial Intelligence. Machine Learning based systems are capable of experiential learning. It can learn from experience and can update itself for better performance [29]. It has lgorithms for classification and prediction. Some of them are Artificial Neural Network, KNN and Principle Component Analysis. Machine Learning is further divided into three parts, which are:
- Supervised Learning: It is used for labelled data. In this type of learning, classification and regression algorithms are included.

- Unsupervised Learning: It is used for unlabeled data. In this type of learning, cluttering and dimensionality reduction algorithms are included.

- Reinforcement Learning: This type of learning is for policy.

C. Smart Learning During Pandemic: Integration of Machine Learning and Education Management System

Figure 3 is showing the hybrid model in which Education Management System (EMS) is integrated with Machine Learning (ML). EMS contains heavy amount of data including lectures, contents, assignments and student's submissions.

The proposed model is designed for the performance improvement of the students. There are multiple phases in the model including data extraction, analysis of data, processing of data, performance check of the students and then a feedback to the system. Detail of each phase is provided below:

1) Data Extraction: First phase of the model involves extraction of data from Education Management Systems, Databases and External Information. Data consist of both structured and unstructured information.

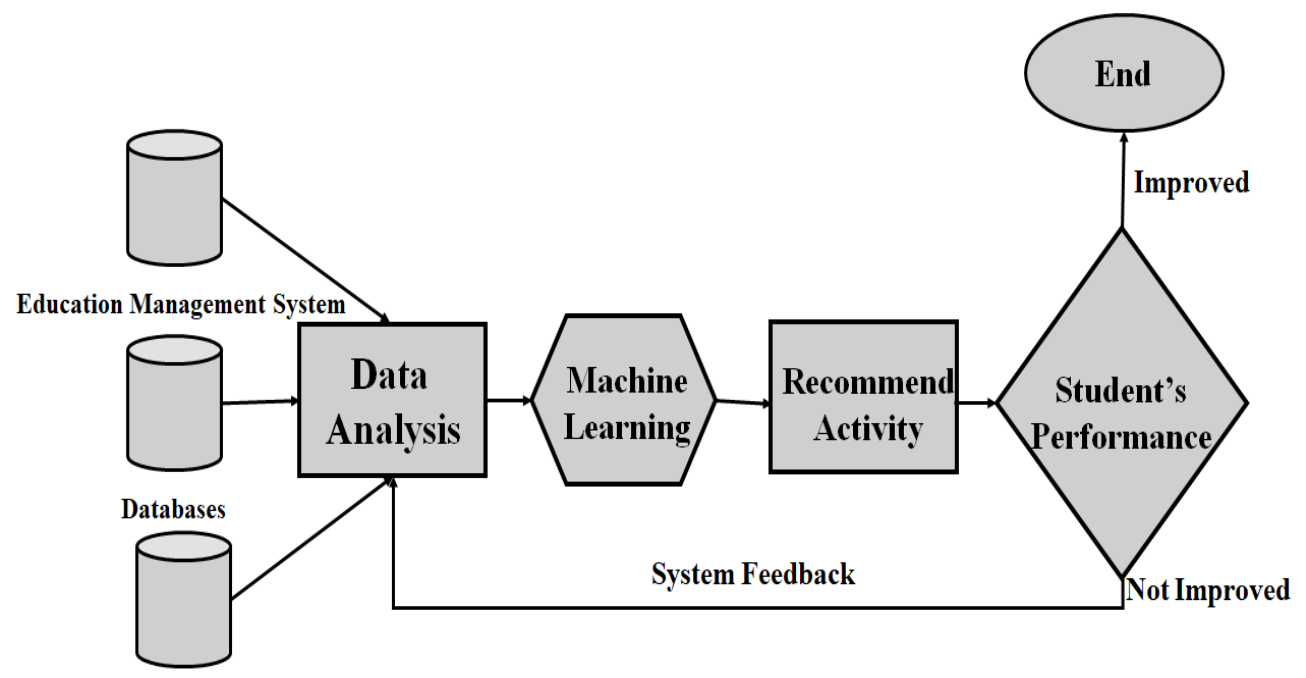

External Information

Fig. 3 Integration of Machine Learning and Education Management System [29] 
2) Analysis of Data: Analysis of data is the second phase of the model. In this phase useful knowledge will be obtained.

3) Data Processing: Now Machine Learning will process the extracted data. With the help of classification algorithms the data will be classified. Machine Learning will predict the changes and will suggest the improvement parameters. For each student it will suggest learning activities to improve performance. Grades will be defined on the basis of institution's policies.

4) Performance Check: In this phase, performance of a student will be checked on the basis of the activity recommended in the previous phase. System will grade the student. If the student improved his performance on the basis of suggested activity, the process will end and return to initial state. If the students do not improve his performance or score satisfactory grade, the process will again start from the analysis of the data.

\section{RESULTS AND DISCUSSION}

Results have been obtained on the basis of faculty and students input on online education. Questions were asked related to the tools which are being used for conducting online classes. Students and Faculty satisfaction on online education and challenges being faced by faculty and students while taking and conducting online classes. Obtained results have been discussed below.
Figure 4 is showing the profession of the responder. There were ten faculty members and forty-six students.

Figure 5 is showing which tools are being used currently for conducting online classes. Out of fiftySeven responders, 47 are using Google Meet, 8 are using Zoom and 2 are using Google Classrooms for conducting online classes.

Figure 6 is showing the satisfaction of teachers and students on the tools which are being used for conducting online classes. 57 people have responded out of which 51 are satisfy with the tools and 6 are dissatisfied.

Figure 7 is showing the responses of faculty and students on the tools they are using for communication. 57 people have responded to the survey out of which 41 people are using WhatsApp, 15 are using Google Meet and 1 is using Email for communication.

Figure 8 is showing the tools which are being used by students and faculty for sharing content/material. 57 people have responded to the question, out of which 28 people are using WhatsApp, 25 are using Learning Management System (LMS) and 4 are using Google Classroom. Figure 9 is showing the input of faculty and students on existence of Failure Management System as a backup. 54 people responded to the question out of which 46 said no and 8 said yes.

Majority of them claim that there is no Failure Management System to make sure the condition of online class in case of any disaster.

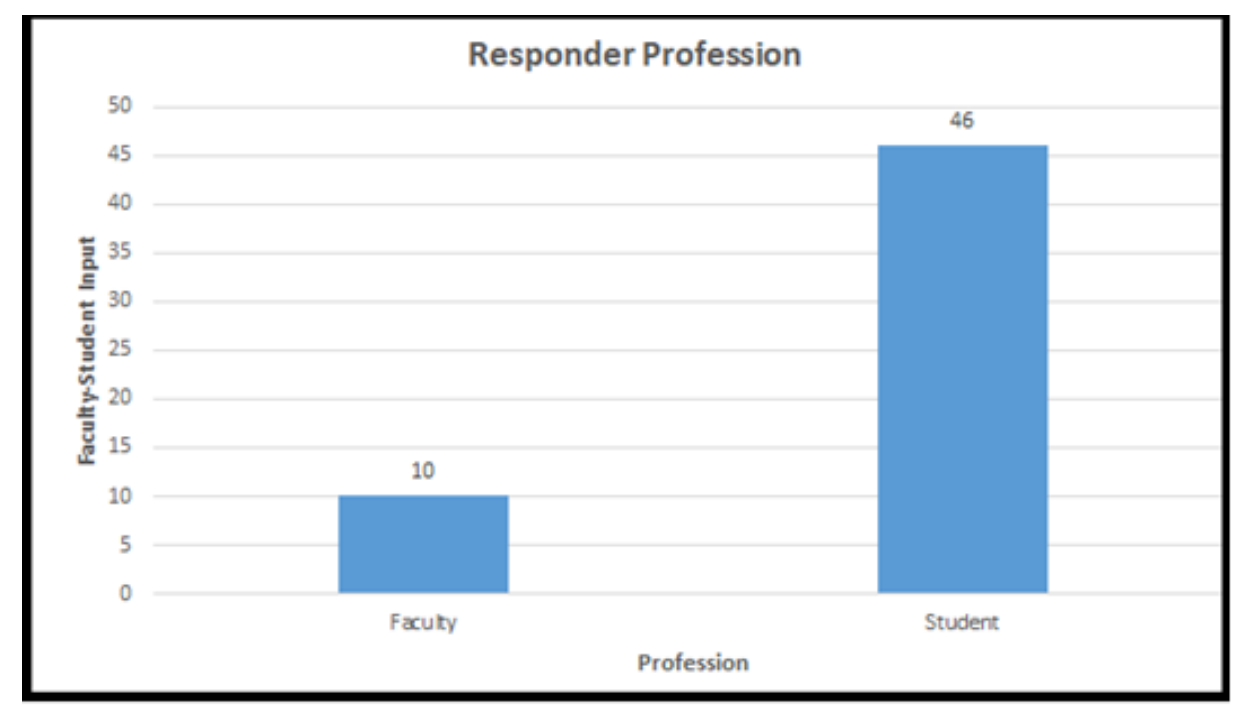

Fig. 4 Responder Profession 


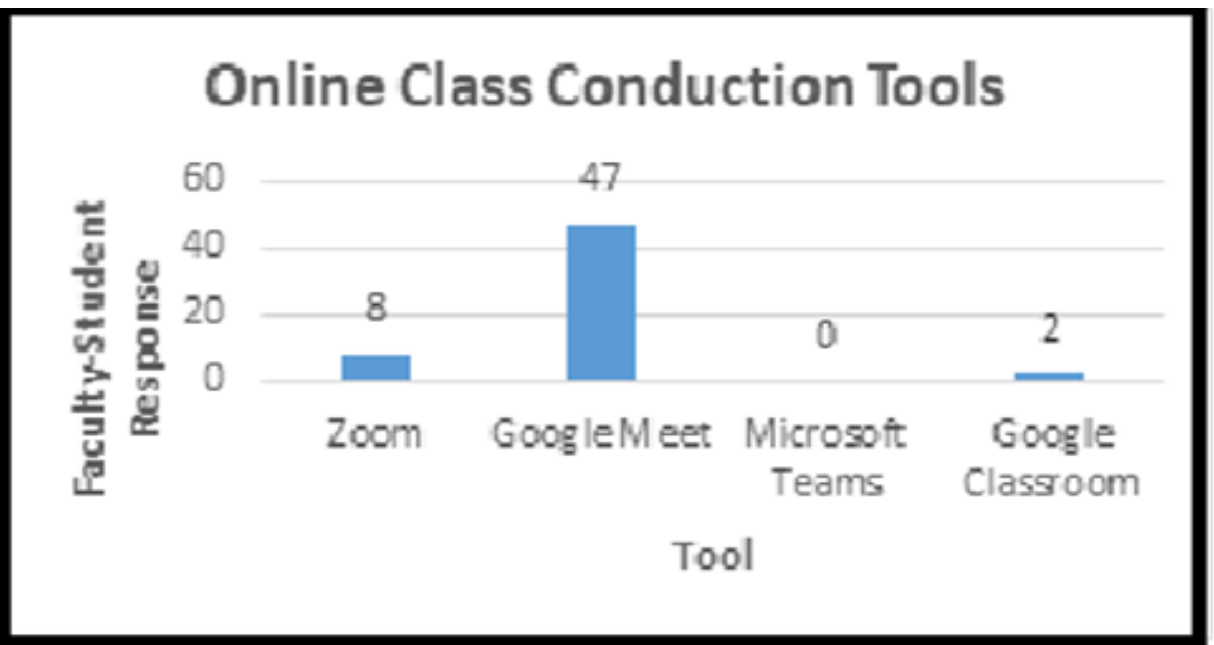

Fig. 5 Online Class Conduction Tools

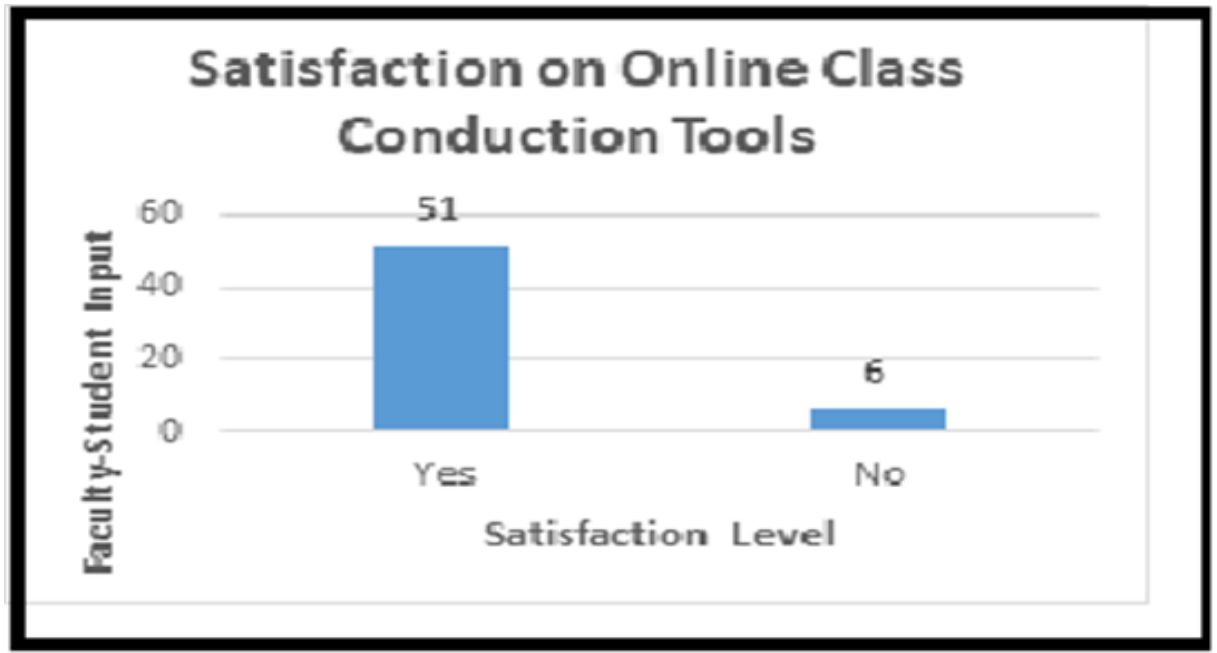

Fig. 6 Satisfaction on Online Class Conduction Tools

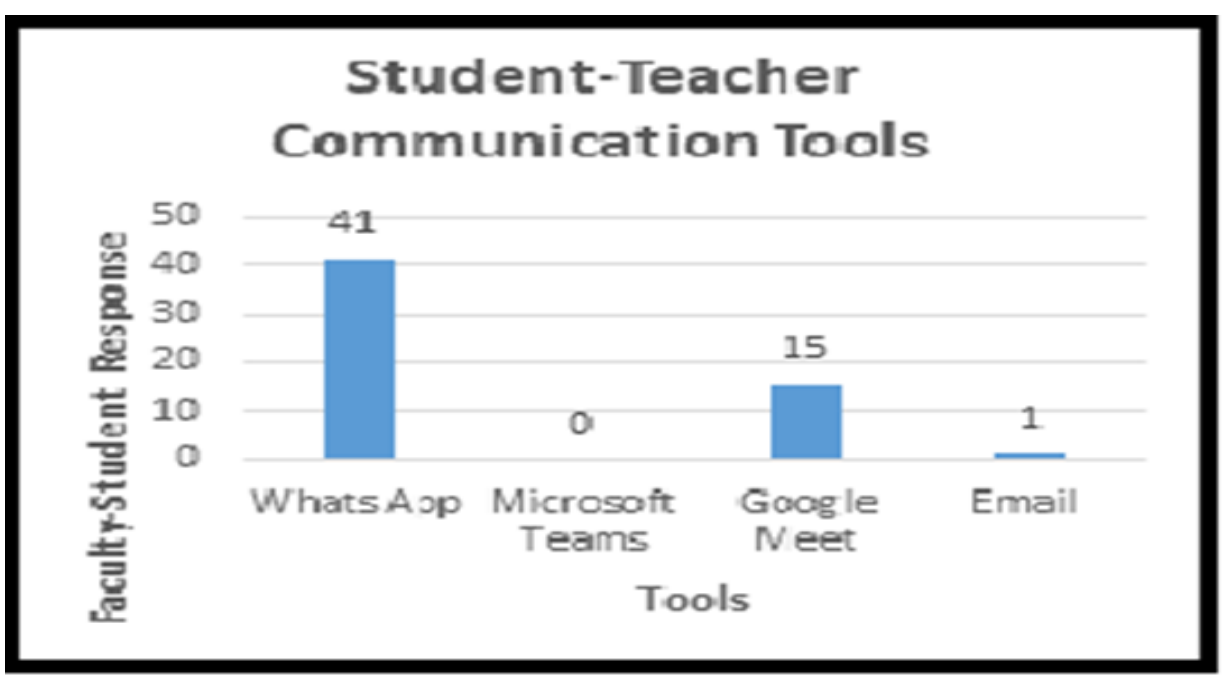

Fig. 7 Student-Teacher Communication Tools 


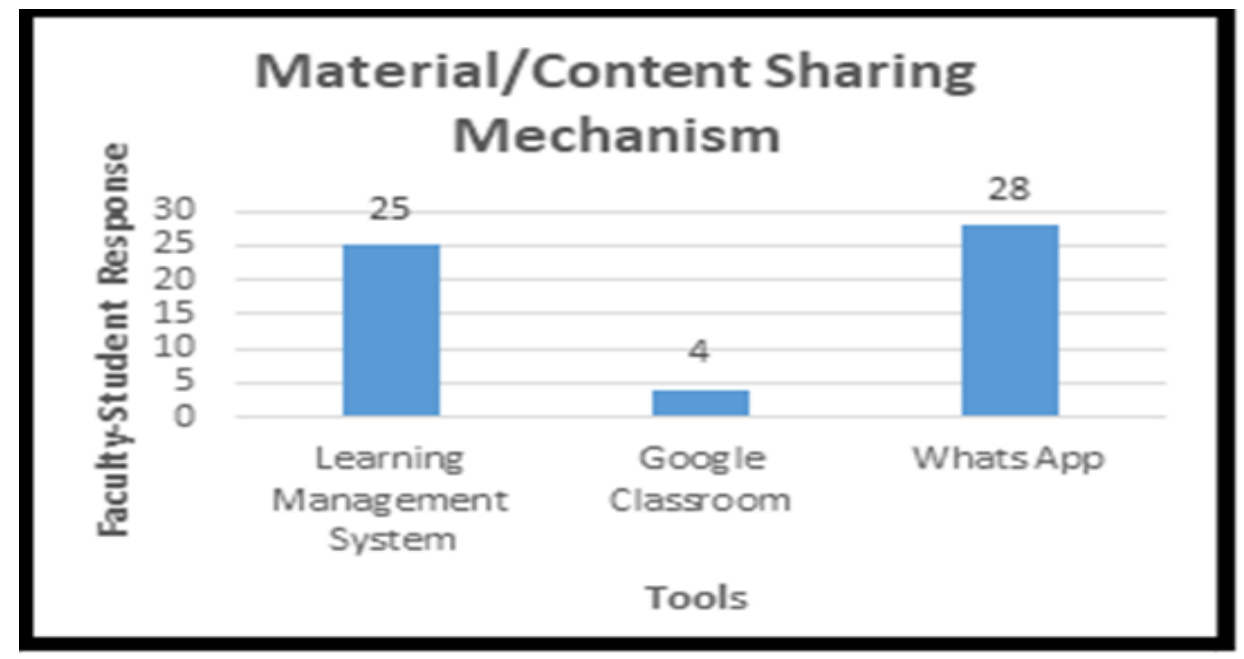

Fig. 8 Material/Content Sharing Mechanism

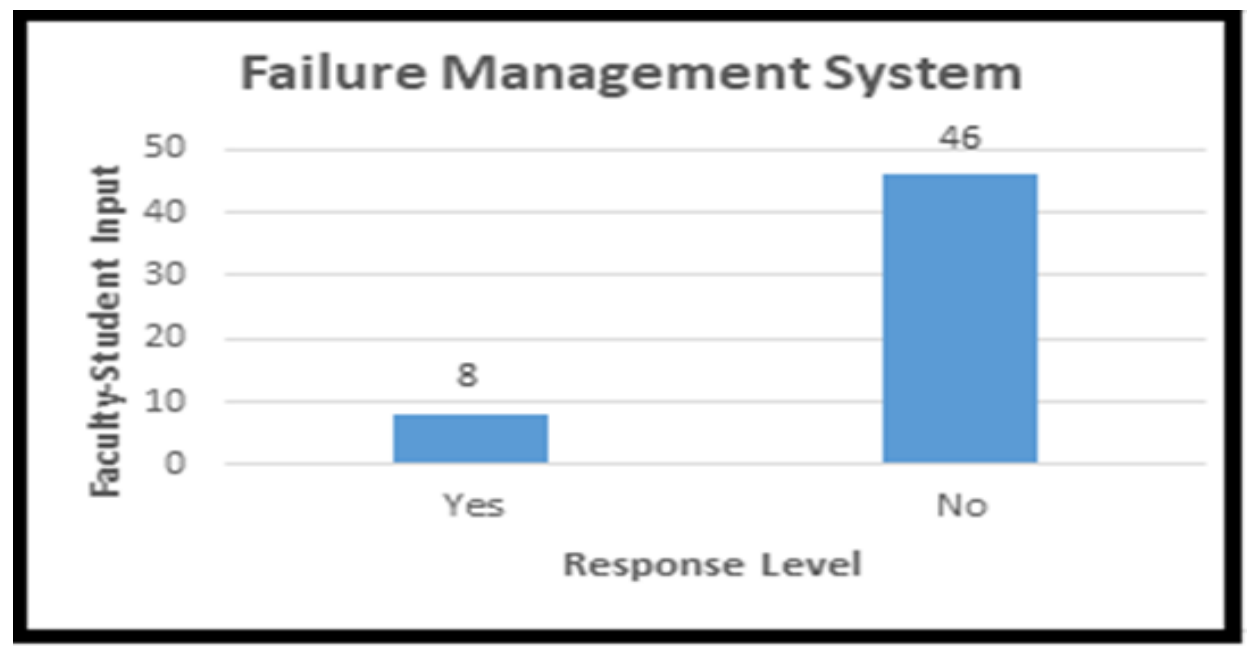

Fig. 9 Failure Management System

\section{CONCLUSION}

Education sector will keep changing. Multiple education models like online model, virtual model and hybrid model are becoming the main actors for research and learning in the field of education. The novel Corona Virus has changed the medium of education from physical to online and hybrid. Students and faculty satisfaction on online education has been obtained. The current tools available for conducting classes online have been identified. A model has been proposed which is based on Artificial Intelligence to support and enhance the effectiveness of online education. For future work, a proposed model can be implemented on the data set to validate the model.

\section{REFERENCES}

[1] D.M Robinson, "Technology and Education in the Twenty- First Century", available: https://www.nfb.org/sites/www.nfb.org/files/images/nfb/publica tions/fr/fr31/2/fr310206.htm, [accessed: 3rd Nov, 2020].

[2] Wogu, I.A.P., F. E. Olu-Owolabi, Assibong P. A, B. C. Agoha, M. Sholarin, A. Elegbeleye, D. Igbokwe, and H. A. Apeh, "Artificial Intelligence, Alienation and Ontological Problems of Other Minds: A Critical Investigation into the Future of Man and Machines", in International Conference on Computing Networking and Informatics (ICCNI), 2017.

[3] Ghafourifar,'14 ways AI will impact the education sector'. Available: https:// venturebeat.com/2017/07/23/14-ways-aiwill-impact-the-education-sector/. [Accessed: 7th October, 2020]

[4] Muacevic , J.R Adler, "Closure of Universities Due to Coronavirus Disease 2019 (COVID-19): Impact on Education and Mental Health of Students and Academic Staff, IN National Center for Biotechnology Information, 2020. DOI: 10.7759/cureus.7541 
[5] B.D Boulay, "Artificial Intelligence as an Effective Classroom Assistant", in IEEE Intelligent Systems Vol. 31, December, 2016.

[6] J. Macleod, H.H Yang, S. Zhu, Y. Li, "Understanding students' preferences toward the smart classroom learning environment: Development and validation of an instrument", in Computers \& Education, Vol. 122, July 2018, Pages 80-91

[7] V.Ratten, "Coronavirus (Covid-19) and the Entrepreneurship Education Community", in Journal of Enterprising Communities: People and Places in the Global Economy, 12 August 2020.

[8] I.A.P Wogu, S.Misra, P.A Assibong, E. Fadeke, R. Maskeliunas and R. Damasevicius, "Artificial Intelligence, Smart Classrooms and Online Education in the 21st Century: Implications for Human Development", in Journal of Cases on Information Technology, vol. 22, September 2019.

[9] M. Chassignol, A. Khoroshavin, A. Klimova, A. Bilyatdinova , "Artificial Intelligence trends in education: a narrative overview", in 7th International young scientist Conference on Computational Science, France, 2018.

[10] Shu-xiao XIE, "Smart Classroom and University Classroom Teaching Innovation" in DEStech Transactions on Computer Science and Engineering, December 2018. DOI: $10.12783 /$ dtcse/iece2018/26602

[11] K.Ilhan, D. Mušić, E. Junuz, S. Mirza, "Scarlet - Artificial Teaching Assistant", in an International Conference on Control, Artificial Intelligence, Robotics \& Optimization (ICCAIRO), 2017.

[12] L. Shen, A.Su, "The Changing Roles of Teachers With AI", in Revolutionizing Education in the Age of AI and Machine Learning, 2020. DOI: 10.4018/978-1-5225-7793-5.ch001

[13] S. Vincent-Lancrin, Reyer van der Vlies, "Trustworthy artificial intelligence (AI) in education Promises and challenges, in OECD Education Working Papers, 2017.

[14] H. Labarthe, V. Luengo, F. Bouchet, "Analyzing the relationships between learning analytics, educational data mining and AI for education" in 4th international conference on Intelligent Tutoring Systems (ITS):Workshop Learning Analytics, Jun 2018, Montreal, Canada. pp.10-19.

[15] D. Newman, S. Hume, L. Lang, "A Systematic Approach for Applying AI Methods on Civilian Applications and Education", in International Journal of Modern Engineering Technologies, Vol. 2, 2020.

[16] Pedro, F. Subosa, M. Rivas, A. Valverde, Paula, "Artificial intelligence in education: challenges and opportunities for sustainable development", 2019.

[17] Berendt, A. Littlejohn, M. Blakemore, "AI in education: learner choice and fundamental rights" in AI and Education: critical perspectives and alternative futures, vol. 2, 2020.

[18] M. Cukurova, "Learning Analytics as AI Extenders in Education: Multimodal Machine Learning versus Multimodal Learning Analytics" in an International Conference on Artificial Intelligence and Adaptive Education, May 2019. DOI: 10.17863/CAM.36128.

[19] Prieto, L. P., Sharma, K., Kidzinski, Ł., Rodríguez-Triana,M. J. Dillenbourg, " Multimodal teaching analytics: Automated extraction of orchestration graphs from wearable sensor data" in Journal of Computer Assisted Learning, 2018, vol.32, pp193203.

[20] P. Asthana, B. Hazela, "Applications of Machine Learning in Improving Learning Environment", in book: Multimedia Big Data Computing for IoT Applications, 2020. DOI: 10.1007/978981-13-8759-3_16.

[21] R.R Halde, "Application of Machine Learning algorithms for betterment in education system", in an International Conference on Automatic Control and Dynamic Optimization Techniques (ICACDOT), 2016.

[22] "Applications of AI," 5 December 2020. [Online]. Available: https://www.javatpoint.com/application-of-ai.
[23] "Smart Classrooms Advantages And Disadvantages|", available: https://eduxpert.in/smart-classrooms-advantagesdisadvantages/, [accessed: 23-Dec-2020].

[24] Smart Classroom vs Traditional Classroom, available: https://medium.com/@ rubyparkpublicschool/smart- classroomvs-traditional-classroom-b52a206c4c37, [accessed: 23-Dec2020].

[25] Teach Thought Staff "10 Roles For Artificial Intelligence In Education" available: https://www.teachthought.com/the-futureof- learning/10-roles-for-artificial-intelligence-in-education/, September 16, 2018, [accessed: 15 Nov, 2020].

[26] G. Supriyanto, I. Widiaty, A G. Abdullah, J Mupita, “Application of expert system for education", in IOP Conference Series: Materials Science and Engineering, 2018.

[27] "Virtual Assistants", available: What is virtual assistant (AI assistant)? - Definition from WhatIs.com (techtarget.com), [accessed: 12-January, 2020\}

[28] "How to use Chatbots for Education and Learning", available:https://www.chatcompose.com/chatbot- learning.html, [accessed: 12-January-2021]

[29] W. Villegas-Ch, M. Román-Cañizares, X. Palacios-Pacheco, "Improvement of an Online Education Model with the Integration of Machine Learning and Data Analysis in an LMS", in Journal of Applied Sciences, 2020. 